\title{
PREVALÊNCIA DE ANTICORPOS CONTRA OS AGENTES DA MAEDI-VISNA E CLAMIDOFILOSE EM OVINOS NO MUNICÍPIO DE UBERLÂNDIA, MG
}

\author{
S.R.S. Salaberry ${ }^{1}$, M.C.C.S.H. Lara ${ }^{2}$, R.M. Piatti ${ }^{2}$, A.F.C. Nassar ${ }^{2}$, \\ J.R. Castro ${ }^{1}$, E.C. Guimarães ${ }^{1}$, A.M.C. Lima-Ribeiro ${ }^{1}$
}

${ }^{1}$ Universidade Federal de Uberlândia, Faculdade de Medicina Veterinária, Av. Ceará, s/n n , CEP 38400-902, Uberlândia, MG, Brasil. E-mail: sandrasalaberry@yahoo.com.br

\section{RESUMO}

\begin{abstract}
Objetivou-se com este estudo realizar o primeiro inquérito soro-epidemiológico para o vírus da maedi-visna e Chlamydophila spp. em 12 rebanhos de ovinos do Município de Uberlândia, MG. Foram utilizadas 334 amostras de soro sanguíneo de ovinos e aplicou-se um inquérito epidemiológico a cada propriedade. Os testes realizados para a pesquisa de anticorpos contra o vírus da maedi-visna e Chlamydophila spp. foram imunodifusão em gel de ágar (IDGA) e reação de fixação do complemento (RFC), respectivamente. Não foram detectados ovinos reagentes para maedi-visna. Verificou-se uma prevalência de 3,3\% para Chlamydophila spp., com títulos variando de 32 a 64 . Não houve diferença estatística significativa $(p>0,05)$ para os fatores de risco analisados. Ressalta-se a importância dos sistemas de vigilância epidemiológica para atuar no controle dessas infecções, evitando a introdução do vírus da maedi-visna e uma maior propagação da Chlamydophila spp. neste município.
\end{abstract}

PALAVRAS-CHAVE: Aborto enzoótico ovino, Chlamydophila spp., IDGA, pneumonia progressiva ovina, reação de fixação de complemento.

\begin{abstract}
PREVALENCE OF ANTIBODIES AGAINST THE AGENTS OF MAEDI-VISNA AND CHLAMYDOPHILOSIS IN SHEEP FROM UBERLÂNDIA COUNTY, MG, BRAZIL. The aim of this study was to carry out the first investigation into the serological prevalence of maedi-visna virus and Chlamydophila spp. on 12 sheep breeding farms in Uberlândia County, MG, Brazil. A total of 334 blood serum samples were used and an epidemiological survey was completed by each farm. The tests to detect maedi-visna and Chlamydophila spp. antibodies were an agar gel immunodiffusion (AGID) and a complement fixation test (CFT), respectively. None of the sheep were reactive to maedi-visna. The detection of antibodies against Chlamydophila spp. was 3.3\%, with titers varying from 32 to 64 . There was no statistically significant difference $(p>0.05)$ in regard to the risk factors analyzed. The importance of epidemiological surveillance systems to aid in the control of these infections is emphasized, in order to avoid the introduction of maedi-visna virus and a wider spread of Chlamydophila spp. in this county.
\end{abstract}

KEY WORDS: Ovine enzootic abortion, Chlamydophila spp., AGID, ovine progressive pneumonia, complement fixation test.

\section{INTRODUÇÃO}

A maedi-visna é uma infecção viral pertencente ao gênero Lentivírus da família Retroviridae eacomete especificamente os ovinos. Maedievisna são palavras de origem islandesas e significam, respectivamente, pneumonia intersticial progressiva crônica e leucoencefalite, que são os principais sinais clínicos que ocorrem nos ovinos (Pritchard; McConnell, 2007). Além da dispneia progressiva e das alterações neurológicas, também pode ocorrer artrite e mastite. Não há evidências da ocorrência desta infecção para humanos (THORMAR, 2005).

Maedi-visna já foi diagnosticada em outros países e está associada a prejuízos econômicos (WolDEMESKEL et al., 2002; FOURNIER et al., 2006). Estudos têm sido realizados no Brasil a fim de verificar a ocorrência da maedi-visna, FeRNANDEs et al. (2003), em um levantamento na microrregião da Grande São Paulo, encontraram 2,8\% de animais sororea-

${ }^{2}$ Instituto Biológico, Centro de Pesquisa e Desenvolvimento de Sanidade Animal, São Paulo, SP, Brasil 
gentes a maedi-visna; ARAújo et al. (2004) relataram a ocorrência de $4,9 \%$ em abatedouros na região metropolitana de Fortaleza; OliveIra et al. (2006) detectaram em abatedouros do Estado de Pernambuco $5,2 \%$ de anticorpos para maedi-visna e em Juazeiro (BA), SouzA et al. (2007) encontraram uma amostra reagente $(0,5 \%)$.

O gênero Chlamydophila é formado por bactérias intracelulares obrigatórias que são divididas em seis espécies, sendo que cada uma está associada a doenças específicas em hospedeiros particulares. Conhecida também como aborto enzoótico dos ovinos, a Chlamydophila abortus (C. abortus) coloniza a placenta de espécies animais, como bovinos, ovinos e caprinos, ocasionando aborto no terço final da gestação. É considerada uma zoonose (LONGBotTom; CoUlter, 2003; AitKen; LONGBOTTOM, 2007).

A clamidofilose está relacionada a prejuízos para a pecuária mundial e ocorre em diversas partes do mundo (Mainar-Jaime et al., 1998; ALQudAH et al., 2004; CisLÁKOVÁ et al., 2007). Silva et al. (2006) afirmaram que existem poucos dados no Brasil sobre a distribuição da $C$. abortus nas diversas espécies animais de produção e ressaltaram a necessidade de se desenvolver pesquisas sobre a associação desta bactéria a problemas reprodutivos no país.

O primeiro estudo sobre a bactéria foi realizado no Município de Belém, PA, onde se isolou o agente etiológico em $70 \%$ das amostras de órgãos e carcaças de bubalinos que apresentaram alterações em um abatedouro (FREITAS; MACHADO, 1988). Posteriormente, estudos sobre a pesquisa da clamidofilose em ovinos foram realizados por PiATTI et al. (2006), que não encontraram anticorpos reagentes anti-Chlamydophila spp. nos estados de São Paulo, Minas Gerais, Mato Grosso e Bahia e Pereira et al. (2009) detectaram a frequência de $8,1 \%$ de anticorpos anti-C. abortus em ovinos no Estado de Pernambuco.

A maedi-visna e a clamidofilose constam na lista de doenças de notificação dos ovinos da Organização Mundial de Saúde Animal, devido ao relevante impacto mundial. Diante da importância econômica e sanitária destas doenças e do crescente interesse na produção de ovinos na região do Triângulo Mineiro, objetivou-se com este estudo realizar o primeiro inquérito soro-epidemiológico para maedi-visna e clamidofilose em ovinos no Município de Uberlândia, MG, bem como associálos aos fatores de risco.

\section{MATERIAL E MÉTODOS}

O estudo foi realizado em 12 rebanhos de ovinos do Município de Uberlândia, MG, selecionados ao acaso, através de cadastros com criações de ovinos fornecidos pela Secretaria Municipal de Agropecuária e Abastecimento deste município. Foram colhidas amostras de sangue, aleatoriamente, de 334 ovinos, aparentemente sadios, sendo 316 fêmeas e 18 machos, com idade variando de seis a maiores de quatro anos, predominantemente mestiças e das raças Dorper e Santa Inês.

A prevalência foi determinada por amostragem aleatória simples, conforme THRUSFIELD (2004), considerando uma prevalência esperada de $31,6 \%$, que foi encontrada por Almeida et al. (2003) em ovinos com sinais clínicos condizentes com a maedi-visna e destinados ao abate na região metropolitana de Fortaleza, CE. Optou-se em adotar a prevalência esperada para maedi-visna, já que esta foi superior aos inquéritos soro-epidemiológicos de clamidofilose realizados em ovinos no Brasil. Utilizou-se um intervalo de confiança de $95 \%$ e erro de estimativa de 0,05 , resultando em uma amostra de 332 ovinos. Para determinar o número de ovinos participantes do experimento por propriedade utilizou-se amostragem estratificada proporcional, de acordo com AYres et al. (2007), onde rebanhos maiores contribuíram com um maior número de animais na amostra final.

Respeitando-se as normas do Comitê de Ética na utilização de animais em pesquisa (aprovado pelo Comitê de Ética na Utilização de Animais: CEUA/ UFU $\left.n^{\circ} 054 / 09\right)$, a colheita de sangue foi realizada por punção da veia jugular, utilizando-se agulhas descartáveis e tubos com vácuo. Após a retração do coágulo sanguíneo, o soro foi transferido para microtubos e congelado a $-22^{\circ} \mathrm{C}$, até o momento de processamento das amostras.

Foram registrados os dados referentes a cada animal como o sexo, idade e raça e aplicou-se um inquérito epidemiológico, de acordo com THrusFIELD (2004), para a identificação dos seguintes fatores de riscos: sistema de manejo, tipo de exploração, assistência veterinária, participação em leilão/exposição e presença de piquete maternidade.

A detecção de anticorpos contra o vírus da maedi-visna foi realizada no Laboratório de Raiva e Encefalites do Instituto Biológico de São Paulo, utilizando-se a técnica de imunodifusão em gel de ágar (IDGA), através do kit comercial (Biovetech $®$ ) para diagnóstico de maedi-visna. A técnica e a leitura foram efetuadas de acordo com as recomendações do fabricante e Almeida et al. (2003).

A pesquisa de anticorpos anti-Chlamydophilaspp. foi executada no Laboratório de Doenças Bacterianas da Reprodução do Instituto Biológico de São Paulo, utilizando a microtécnica da Reação da Fixação do Complemento(RFC), deacordocom Donnetal.(1997) e conforme recomendada pela Organização Mundial 
de Saúde Animal (World Organisation for ANimal HeALTH, 2008). A reação foi realizada em microplacas utilizando-se soro teste nas diluições de 1:16 a 1:512, o antígeno C. abortus cepa S26/3 na diluição 1:50 e o complemento na diluição correspondente a duas unidades fixadoras de complemento. Como soro controle positivo, utilizou-se soro bovino com título 512 para C. abortus, gentilmente cedido pelo Dr. Carlo Turilli do Instituto Zooprofilattico Sperimentalle delle Venezie Itália-IZSV, e como soro controle negativo utilizou-se soro fetal bovino. Após incubação a $37^{\circ} \mathrm{C}$ por 30 minutos, adicionou-se na microplaca o sistema hemolítico eincubou-se por mais 30 minutos. Posteriormente, as microplacas foram centrifugadas e em seguida efetuada a leitura visual. A recíproca da maior diluição de soro apresentando $50 \%$ de fixação do complemento determinou o título de anticorpos anti-Chlamydophila spp.

Devido à possibilidade de reação cruzada entre C. abortus e C. pecorum, foram consideradas reagentes as amostras com título igual ou superior a 32, e suspeitas as amostras com título igual a 16, conforme Donn et al. (1997).

Para o cálculo da prevalência, utilizou-se porcentagem simples e para associar os resultados obtidos com os fatores de risco, utilizou-se o teste não paramétrico Odds Ratio, com nível de significância de 5\%, de acordo com AYres et al. (2007).

\section{RESULTADOS E DISCUSSÃO}

Todos os ovinos $(\mathrm{n}=334)$ não reagiram ao teste de IDGA para maedi-visna e, portanto, não houve associação significativa com os fatores de risco. A ovinocultura é uma atividade recente na região, $58,3 \%$ dos produtores relataram que compram ovinos em outros municípios da região e 41,7\% compram em outros estados do país. Ovinos procedentes de outras regiões onde se desconhece a epidemiologia desta infecção e propriedades sem histórico podem ser fontes de introdução do agente responsável por esta doença em um novo rebanho, o que ainda não ocorreu com a maedi-visna no Município de Uberlândia.

Resultados diferentes foram encontrados em outras regiões, como por ARAújo et al. (2004), que determinaram prevalência de $4,9 \%$ de anticorpos contra o vírus da maedi-visna pelo teste do IDGA em abatedouros, além de encontrarem lesões pulmonares sugestivas desta doença. Em São Paulo, FERNANDES et al. (2003) detectaram uma prevalência de 2,8\%; em Pernambuco, 5,2\% (Oliveira et al., 2006) e em Araçatuba, SP, 2,7\% dos ovinos apresentaram anticorpos reagentes ao IDGA (LOMBARDI et al., 2009). Estes resultados demonstraram que o vírus pode estar sendo introduzido em diferentes regiões do país, embora a prevalência encontrada ainda é baixa.

A prevalência baixa deste vírus podeestar relacionada ao fato de que a maioria das criações de ovinos do país adotou o sistema semiextensivo ou extensivo. Em Juazeiro, BA, SouzA et al. (2007) encontraram uma prevalência de $0,5 \%$ de anticorpos contra o vírus da maedi-visna e possuíam predominantemente o sistema de criação extensivo, o que pode justificar os resultados obtidos neste estudo, já que somente $25 \%$ rebanhos pesquisados utilizavam o sistema intensivo.

Inquéritos soro-epidemiológicos realizados em outros países para verificar a prevalência da maedivisna demonstraram que a sua ocorrência é maior do que a encontrada no Brasil. Como por WOLDEMESKEL et al. (2002), que diagnosticaram a ocorrência de $74 \%$ dos ovinos reagentes contra o vírus da maedi-visna na Etiópia e FourNiER et al. (2006) que detectaram 13\% de ovinos reagentes em Alberta, ambos realizados pelo teste do IDGA. ARSENAULT et al. (2003) encontraram $44 \%$ de anticorpos de ovinos reagentes ao teste de ELISA contra o vírus da maedi-visna em dois frigoríficos do Quebec, Canadá. Além de utilizarem outros testes sorológicos, a sensibilidade do IDGA pode variar de acordo com o antígeno utilizado. A proteína viral gp135 confere maior sensibilidade à técnica do que a p28 (ADAMS; GoRHAM, 1986), o que dificulta a comparação com a prevalência encontrada em outros países.

A frequência de ovinos reagentes para Chlamydophila spp. foi 3,3\% (11/334), apresentando títulos variando de 32 a 64, e para ovinos suspeitos, a frequência foi 7,5\% (25/334). Do total dos rebanhos estudados, seis (50\%) foram reagentes para a pesquisa de Chlamydophila spp., cinco (41,7\%) foram suspeitose quatro $(33,3 \%)$ foram nãoreagentes, sendoquealguns apresentaram tanto ovinos reagentes como suspeitos. A porcentagem de reagentes por propriedade variou de 2,3\% a 33,3\% (Tabela 1). Estes resultados demonstraram que em $50 \%$ dos rebanhos háfocos de infecção, podendo indicar uma disseminação entre os rebanhos de ovinos da região.

Pereira et al. (2009) encontraram no Estado de Pernambuco resultados superiores ao deste estudo, onde detectaram uma frequência de anticorpos antiC. abortus em dez $(8,1 \%)$ ovinos. Piatti et al. (2006) não detectaram ovinos reagentes em rebanhos dos estados deSão Paulo, de Minas Gerais, Mato Grosso e Bahia. Ressalta-se que o presente estudo foi realizado no Triângulo Mineiro, MG, em diferente região da pesquisada por PiatTI et al. (2006), demonstrando a variação de resultados que pode ocorrer entre regiões distintas. Por isso é importante a realização de inquéritos soro-epidemiológicos em diferentes locais do país, a fim de se conhecer a prevalência desta bactéria. 
Tabela 1 - Distribuição dos títulos de anticorpos anti-Chlamydophila spp. em ovinos por propriedade no Município de Uberlândia, MG, 2009.

\begin{tabular}{cccccccc}
\hline \multirow{2}{*}{ Propriedades } & $\mathrm{N}$ & $\mathrm{n}$ & Não reagente $(\%)$ & \multicolumn{3}{c}{ Título (\%) } & $\begin{array}{c}\text { Total de reagente } \\
(\%)\end{array}$ \\
\hline A & 345 & 24 & $24(100)$ & 16 & 32 & 64 & - \\
B & 591 & 43 & $42(97,7)$ & - & - & - & $1(2,3)$ \\
C & 153 & 14 & $14(100)$ & - & - & - & - \\
D & 382 & 30 & $30(100)$ & - & - & - & - \\
E & 580 & 41 & $41(100)$ & - & - & - & - \\
F & 165 & 12 & $11(91,7)$ & $1(8,3)$ & - & - & - \\
G & 500 & 35 & $30(85,7)$ & $3(8,6)$ & $1(2,9)$ & $1(2,9)$ & $2(5,8)$ \\
H & 1000 & 70 & $63(90)$ & $3(4,3)$ & $3(4,3)$ & $1(1,4)$ & $4(5,7)$ \\
I & 512 & 38 & $21(55,3)$ & $16(42,1)$ & $1(2,6)$ & - & $1(2,6)$ \\
J & 200 & 15 & $13(86,7)$ & $2(13,3)$ & - & - & - \\
L & 35 & 3 & $2(66,7)$ & - & $1(33,3)$ & - & $1(33,3)$ \\
M & 90 & 9 & $7(77,8)$ & - & $2(22,2)$ & - & $2(22,2)$ \\
\hline
\end{tabular}

${ }^{\mathrm{N}}$ Total de ovinos existente em cada propriedade.

n Total de ovinos utilizado no experimento.

Tabela 2 - Frequência de ovinos reagentes a Chlamydophila spp. de acordo com o sexo, idade e raça, em rebanhos de ovinos do Município de Uberlândia, MG, 2009.

\begin{tabular}{|c|c|c|c|c|c|}
\hline \multirow{2}{*}{ Característica } & \multicolumn{2}{|c|}{ Ovinos } & \multirow{2}{*}{$\mathrm{OR}^{\mathrm{a}}$} & \multirow{2}{*}{$\mathrm{IC}^{\mathrm{b}} 95 \%$} & \multirow{2}{*}{$\mathrm{P}$} \\
\hline & Total & Reagente & & & \\
\hline \multicolumn{6}{|l|}{ Sexo } \\
\hline Macho & 18 & - & - & - & - \\
\hline Fêmea & 316 & 11 & & & \\
\hline \multicolumn{6}{|l|}{ Idade } \\
\hline $6 \mathrm{a}<12$ meses & 62 & 2 & $0,92^{c}$ & $0,18-4,67$ & 0,76 \\
\hline $1 \mathrm{a}<4$ anos & 101 & 3 & & & \\
\hline$\geq 4$ anos & 171 & 6 & & & \\
\hline \multicolumn{6}{|l|}{ Raça } \\
\hline Dorper & 26 & - & 2,39 & $0,68-8,32$ & 0,28 \\
\hline Santa Inês & 131 & 7 & & & \\
\hline Outras raças & 4 & - & & & \\
\hline Mestiças & 173 & 4 & & & \\
\hline
\end{tabular}

a Odds Ratio.

${ }^{\mathrm{b}}$ Intervalo de confiança.

${ }^{\mathrm{c}} \mathrm{OR}$ para a maior diferença entre proporções.

Se $p<0,05$ existe diferença significativa.

Os títulos de anticorpos encontrados por PEREIRA et al. (2009), de maneira geral, também foram baixos. O maior título encontrado neste estudo foi 64 e, por
Pereira et al. (2009), foi 128. Na República Eslovaca, CisLÁKová et al. (2007) encontraram 11,7\% de anticorpos anti-Chlamydophila spp. e os títulos variaram de 
Tabela 3 - Frequência de ovinos reagentes a Chlamydophila spp. de acordo com os fatores de risco em rebanhos do Município de Uberlândia, MG, 2009.

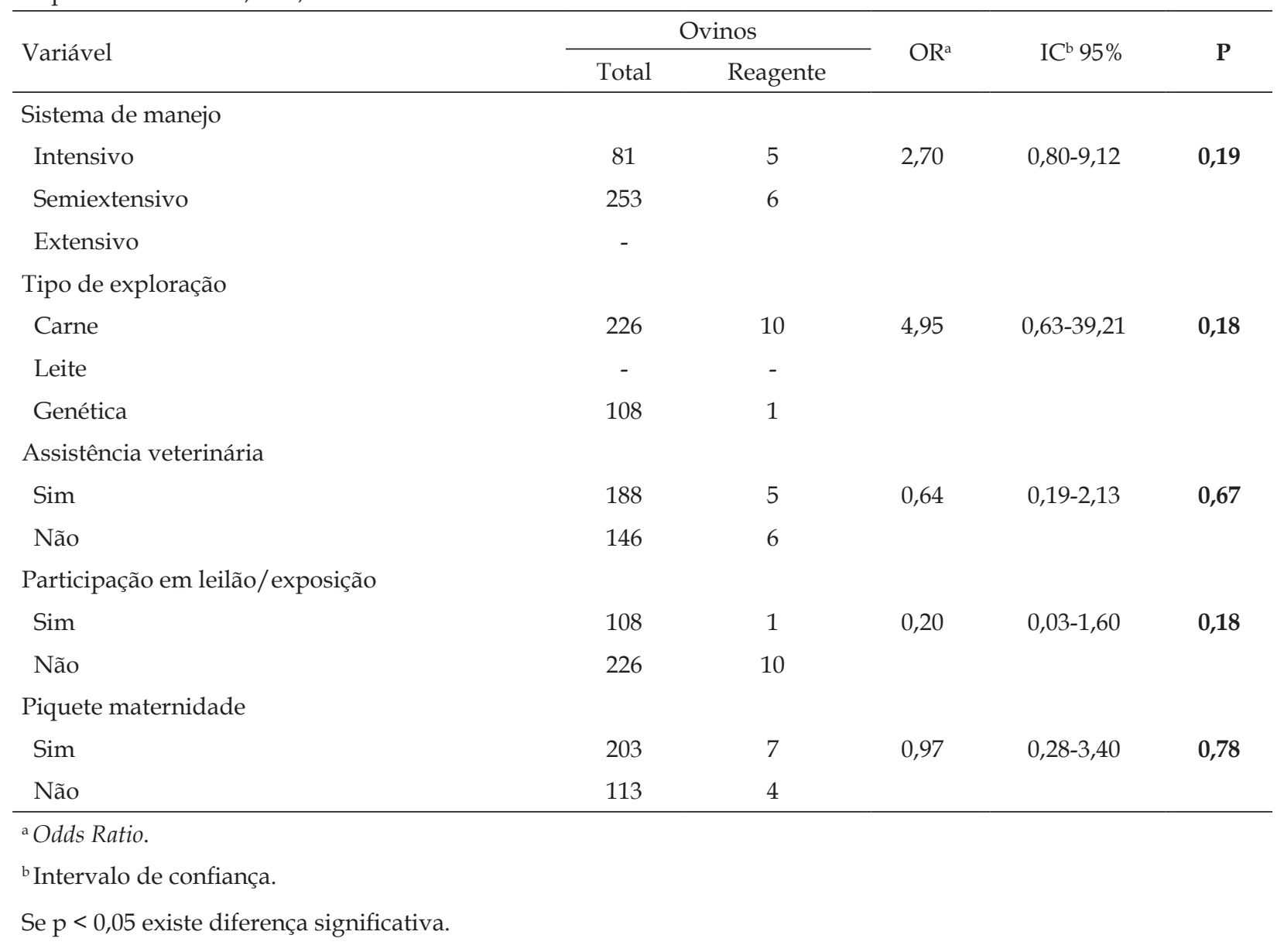

64 a 4096. Este título elevado é detectado em casos de suspeita de aborto por Chlamydophila spp. (CisLÁKOVÁ et al., 2007), o que não ocorreu neste estudo, cuja colheita de sangue foi aleatória e os ovinos não apresentavam problemas reprodutivos.

A reação cruzada entre C. abortus e C. pecorum pode resultar em falsos positivos com títulos baixos. Assim, títulos menores do que 32 são considerados não específicos para C. abortus (World OrganisAtion for Animal Health, 2008). A C. pecorum afeta ruminantes e pode causar pneumonia, conjuntivite, poliartrite, metrite, encefalite e doenças entéricas (KeRr et al., 2005).

Nãohouvediferençaestatísticasignificativa $(p>0,05)$ entreas amostras reagentes para Chlamydophila spp. eas variáveis idade e raça, assim as diferentes idades eraças apresentaram a mesma suscetibilidade a infecção pela clamidofilose. Todos os machos foram não reagentes a reação de fixação de complemento (Tabela 2).

AL-QUDAH et al. (2004) também não identificaram diferença estatística significativa ao associar a prevalência de anticorpos anti-Chlamydophila spp. com a idade dos ovinos e estas variaram de um ano a maiores que quatro anos. Ao associar a prevalência de anticorpos anti-Chlamydophila spp. com ovinos mestiços e de raças puras, PEREIRA et al. (2009) não encontraram diferença estatística significativa, assim como ocorreu neste estudo.

Poucas são as evidências de transmissão venérea, embora tenha sido isolada a C. abortus de sêmen e glândulas sexuais acessórias de carneiro, esta via de transmissão parece não contribuir na epidemiologia da infecção desta bactéria (LongBotTom; Coulter, 2003). AitKen; LongBottom (2007) relataram que os restos placentários da ovelha são a principal fonte de transmissão deste agente.

Não houve diferença estatística significativa ( $p$ > 0,05 ) entre os ovinos reagentes para Chlamydophila spp. e os fatores de risco (Tabela 3).

MAINAR-JAIME et al. (1998) concluíram que a soroprevalência da clamidofilose foi menor em propriedades com exploração do corte, onde os ovinos foram criados em sistemas extensivos, do que propriedades leiteiras, onde ficavam confinados. Apesar de não ocorrer risco significativo entre os tipos de manejo em relação à proporção de ovinos reagentes, isto poderia 
justificar os resultados encontrados, onde somente três propriedades criavam ovinos confinados, sendo que o restante das propriedades utilizava o sistema semiextensivo, onde os animais permaneciam soltos durante o dia e presos à noite. Além disso, o tipo de exploração predominante foi o corte, seguido pelo melhoramento genético e sem a existência de ovinocultura leiteira neste município.

De acordo com o inquérito epidemiológico, apenas 56,3\% dos rebanhos possuíam assistência veterinária, estando o restante destas propriedades sem acompanhamento do manejo sanitário. Esta porcentagem se aproxima da encontrada por GoUvEIA et al. (2009) que concluíram que apenas 58,8\% das propriedades de ovinos do Estado de Minas Gerais possuíam assistência veterinária. Este índice é preocupante, pois, além de prejudicar o desenvolvimento da ovinocultura na região, muitas doenças podem não ser diagnosticadas, como a maedi-visna e o aborto relacionado à clamidofilose.

Os fluídos liberados junto com a placenta e a pele de cordeiro contaminados são as principais fontes de contaminação para o meio ambiente (LONGBOTTOM; COULTER, 2003). Assim, aglomeração de ovinos em leilão/exposição de diferentes origens, se não controlada, pode favorecer a disseminação do agente responsável pela clamidofilose. Da mesma forma, a ausência de piquete maternidade para ovelhas em gestação também favorece a disseminação do agente. De acordo com o inquérito epidemiológico realizado, 35,8\% das ovelhas não foram separadas em piquetes maternidade.

Ressalta-se a importância da Chlamydophila spp. para a saúde pública, já que existem relatos sobre casos de transmissão deste agente para funcionários de abatedouros, bem como para mulheres grávidas que trabalham em fazendas e têm contato com ovinos infectados (AITKEN; LONGBOTTOM, 2007).

\section{CONCLUSÕES}

Os resultados demonstram a presença de anticorpos anti-Chlamydophila spp. em ovinos no Município de Uberlândia, MG. Infere-se que a infecção esta bactéria pode estar disseminada nos rebanhos de ovinos desta região. Ressalta-se a importância dos sistemas de vigilância epidemiológica para atuar no controle destas infecções, evitando a introdução da maedi-visna e uma maior propagação da clamidofilose neste município.

\section{REFERÊNCIAS}

ADAMS, D.S.; GORHAM, J.R. The gp135 of caprine arthritis encephalitis virus affords greater sensitivity than the $\mathrm{p} 28$ in immunodifusion serology. Research in Veterinary Science, v.40, p.157-160, 1986.

AITKEN, I.D.; LONGBOTTOM, D. Chlamydial abortion. In: AITKEN, I.D. (Ed.). Diseases of sheep. 4.ed. Edinburg: Blackwell, 2007. p.105-112.

ALMEIDA, N.C.; TEIXEIRA, M.F.S.; FERREIRA, R.C.S.; CALLADO, A.K.C; FROTA M.N.L.; MELO, A.C.M.; APRÍGIO, C.J.L. Detecção de ovinos soropositivos para maedi/visna destinados ao abate na região metropolitana de Fortaleza. Veterinária Notícias, v.9, n.1, p.59-63, 2003.

AL-QUDAH, K.M.; SHARIF, L.A.; RAOUF, R.Y.; HAILAT, N.Q.; AL-DOMY, F.M. Seroprevalence of antibodies to Chlamydophila abortus shown in Awassi sheep and local goats in Jordan. Veterinary Medicine Czechoslovakia, v.49, p.460-466, 2004.

ARAÚJO, S.A.C.; DANTAS, T.V.M.; SILVA, J.B.A.; RIBEIRO, A.L.; RICARTE, A.R.F.; TEIXEIRA, M.F.S. Identificação do maedi-visna vírus em pulmão de ovinos infectados naturalmente. Arquivos do Instituto Biológico, São Paulo, v.71, n.4, p.431-436, 2004.

ARSENAULT, J.; GIRARD, C.; DUBREUIL, P.; DAIGNAULT, D.; GALARNEAU, J.R.; BOISCLAIR, J.; SIMARD, C.; BÉLANGER, D. Prevalence of and carcass condemnation from maedi-visna, paratuberculosis and caseous lymphadenitis in culled sheep from Quebec, Canada. Preventive Veterinary Medicine, v.59, p.67-81, 2003.

AYRES, M.; AYRES, JR.M.; AYRES, D.L.; SANTOS, A.A.S. Bioestat 5.0. Aplicações estatísticas nas áreas das ciências bio-médicas. Belém: Sociedade Mamiaurá/ Imprensa Oficial do Estado do Pará, 2007.

CISLÁKOVÁ, L.; HALANOVA, M.; KOVACOVA, D.; STEFANCIKOVA, A. Occurrence of antibodies against Chlamydophila abortus in sheep and goats in the Slovak Republic. Annals of Agricultural and Environmental Medicine, v.14, p.243-245, 2007.

DONN, A.; CARNIELETTO, P.; CHIARACANE, G.; LADU, M.; MACHELL, J.; MANDOLA, M.I.; RUIU, A.; STANCANELLI, A.; TURILLI, C. Standardizzazione della tecnica di fissazionedel complemento per la dimostrazione di anticorpi anti Chlamydia nel siero di sangue. Progresso Veterinário, v.4, p.125-128, 1997.

FERNANDES, M.A.; ARAÚJO W.P.; CASTRO, R.S. Prevalência da infecção pelo vírus maedi-visna em ovinos da microrregião Grande São Paulo, estado de São Paulo. Ciência Veterinária Tropical, v.6, n.1, p.23-28, 2003.

FOURNIER, D.; CAMPBELL, J.R.; MIDDLETON, D.M. Prevalence of maedi-visna infection in culled ewes in Alberta. Canadian Veterinary Journal, v.47, p.460-466, 2006. 
FREITAS, J.A.; MACHADO, R.D. Isolamento de Chlamydia psittaci em búfalos abatidos para consumo em Belém, Pará. Pesquisa Veterinária Brasileira, v.8, n.3/4, p.43-50, 1988.

GOUVEIA, A.M.G.; GUIMARÃES, A.S.; HADDAD, J.P.A.; ABREU, C.P.; CRUZ, J.C.M., CARMO, F.B.

Características zoosanitárias da ovinocultura em Minas Gerais, Brasil. In: ACCOMG, 2009. Disponível em: $<$ http://www.caprileite.com.br/conteudo.php?id_ conteudo $=88 \& i d \_l i n k s=4 \& i d \_s u b \_l i n k s=28$ Sitewww . accomig.com.br>. Acesso em: 25 ago. 2009.

KERR, K.; ENTRICAN, G.; MCKEEVER, D.; LONGBOTTOM, D. Immunopathology of Chlamydophila abortus infection in sheep and mice. Research in Veterinary Science, v.78, p.1-7, 2005.

LOMBARDI, A.L.; NOGUEIRA, A.H.C.; FERES, F.C.; PAULO, H.P.; CASTRO, R.S.; FEITOSA, F.L.F.; CADIOLI, F.A.; PEIRÓ, J.R.; PERRI, S.H.V; LIMA, V.F.M.; MENDES, L.C.N. Soroprevalência de maedi-visna em ovinos na região de Araçatuba, SP. Arquivo Brasileiro de Medicina Veterinária e Zootecnia, v.61, n.6, p.1434-1437, 2009.

LONGBOTTOM, D.; COULTER, J. Animal chlamydioses and zoonotic implications. Journal of Comparative Pathology, v.128, p.217-244, 2003.

MAINAR-JAIME, R.C.; CRUZ, C.; VÁZQUEZ-BOLAND, J.A. Epidemiologic study of chlamydial infection in sheep farms in Madrid, Spain. Small Ruminant Research, v.28, p.131-138, 1998.

OLIVEIRA, M.M.M.; CASTRO, R.S.; CARNEIRO, K.L.; NASCIMENTO, S.A.; CALLADO, A.K.C.; ALENCAR, C.S.A.; COSTA, L.P.S. Anticorpos contra lentivírus de pequenos ruminantes em caprinos e ovinos em abatedouros do estado de Pernambuco. Arquivo Brasileiro de Medicina Veterinária e Zootecnia, v.58, n.5, p.947-949, 2006.

PEREIRA, M.F.; PEIXOTO, R.M.; PIATTI, R.M.; MEDEIROS, E.S.; MOTA, I.O., AZEVEDO, S.S.; MOTA, R.A.
Ocorrência e fatores de risco para Chlamydophila abortus em ovinos e caprinos no estado de Pernambuco. Pesquisa Veterinária Brasileira, v.29, n.1, p.33-40, 2009.

PIATTI, R.M.; SCARCELLI, E.P.; GENOVEZ, M.E. Pesquisa de anticorpos anti-Chlamydophila em caprinos e ovinos. Biológico, São Paulo, v.68, n.1/2, p.138-140, 2006.

PRITCHARD, G.C.; MCCONNELL, I. Maedi-visna. In: AITKEN, I.D. (Ed.). Diseases of sheep. 4.ed. Edinburg: Blackwell, 2007. p.217-223.

SILVA, F.G.; FREITAS, J.C.; MULLER, E.E. Chlamydophila abortus em animais de produção. Ciência Rural, v.36, n.1, p.342-348, 2006.

SOUZA, T.S.; COSTA, J.N.; MARTINEZ, P.M.; PINHEIRO, R.R. Estudo sorológico da maedi-visna pelo método da imunodifusão em gel de ágar em rebanhos ovinos de Juazeiro, Bahia, Brasil. Revista Brasileira de Saúde e Produção Animal, v.8, n.4, p.276-282, 2007.

THORMAR, H. Maedi-visna vírus and its relationship to human immunodeficiency vírus. AIDS Reviews, v.7, p.233-245, 2005.

THRUSFIELD, M. Epidemiologia veterinária. 2.ed. São Paulo: Roca, 2004. 556p.

WOLDEMESKEL, M.; TIBBO, M.; POTGIETER, L.N.D. Ovine progressive pneumonia (Maedi-Visna): An emerging respiratory disease of sheep in Ethiopia. Deutsche Tierärztliche Wochenschrift, v.109, p.486-488, 2002.

WORLD ORGANISATION FOR ANIMAL HEALTH. Enzootic abortion of ewes (ovine chlamydioses). OIE Terrestrial Manual. 2008. Disponível em: <2008http:// www.oie.int/eng/normes/mmanual/2008/pdf/ 2.07.07_ENZ_ABOR.pdf>. Acesso em: 25 jul. 2009.

Recebido em 3/3/10

Aceito em 5/8/10 